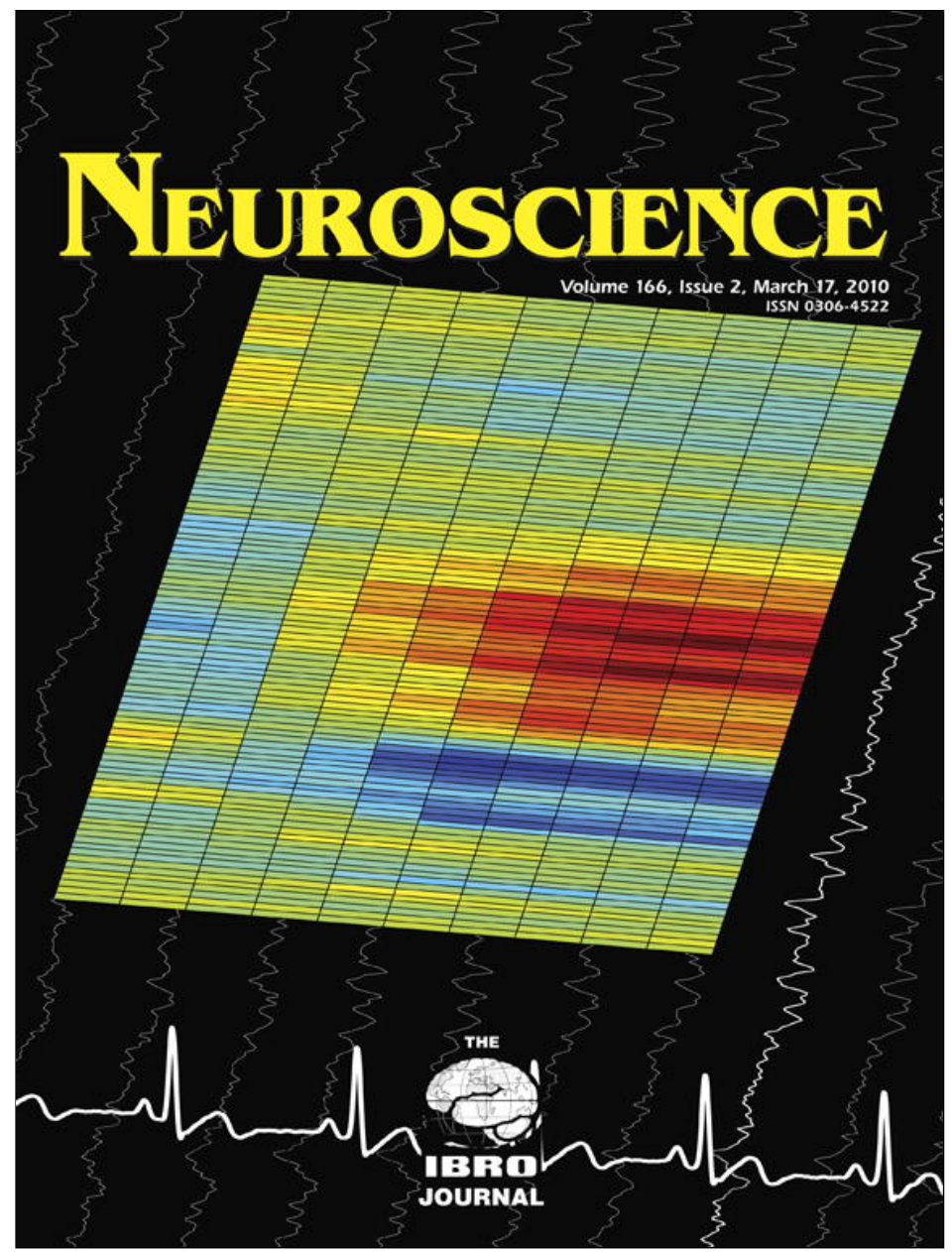

This article appeared in a journal published by Elsevier. The attached copy is furnished to the author for internal non-commercial research and education use, including for instruction at the authors institution and sharing with colleagues.

Other uses, including reproduction and distribution, or selling or licensing copies, or posting to personal, institutional or third party websites are prohibited.

In most cases authors are permitted to post their version of the article (e.g. in Word or Tex form) to their personal website or institutional repository. Authors requiring further information regarding Elsevier's archiving and manuscript policies are encouraged to visit: 


\section{SHORT TERM TREATMENT WITH ESTRADIOL DECREASES THE RATE OF NEWLY GENERATED CELLS IN THE SUBVENTRICULAR ZONE AND MAIN OLFACTORY BULB OF ADULT FEMALE MICE}

\author{
O. BROCK, ${ }^{a}$ M. KELLER, ${ }^{b}$ A. VEYRAC, ${ }^{c}$ Q. DOUHARD ${ }^{a}$ \\ AND J. BAKKER ${ }^{a *}$ \\ ${ }^{a}$ GIGA-Neurosciences, University of Liege, Avenue de l'Hôpital 1 \\ (B36), 4000 Liege, Belgium \\ ${ }^{b}$ Behavioral and Reproductive Physiology, UMR 6175 INRA/CNRS/ \\ University of Tours, Nouzilly, France \\ 'Laboratoire de Neurobiologie de l'Apprentissage, de la Mémoire et de \\ la Communication, CNRS UMR 8620, University Paris-Sud XI, Orsay, \\ France
}

\begin{abstract}
Adult neurogenesis occurs most notably in the subgranular zone (SGZ) of the hippocampal dentate gyrus and in the olfactory bulb (OB) where new neurons are generated from neural progenitors cells produced in the subventricular zone (SVZ) of the forebrain. As it is well known that gonadal steroid hormones, primarily estradiol, modulate neurogenesis in the hippocampus of adult female rodents, we wanted to determine whether estradiol would also affect the proliferation of progenitor cells in the SVZ and by consequence the rate of newly generated cells in the main OB. Thus a first group of adult female C57BI6/J mice was ovariectomized and received a short term treatment with estradio (single injection of 1 or $10 \mu \mathrm{g} 17 \beta$-estradiol or Silastic capsule of estradiol during 2 days) before receiving a single injection with BrdU to determine whether estradiol would modulate the cell proliferation in the SVZ. A second group of adult ovariectomized female mice was submitted to the same estradiol treatment before receiving four BrdU injections, and was sacrificed 21 days later to determine whether a modulation in cell proliferation actually leads to a modulation in the number of newborn cells in the main $O B$. We observed a decrease in cell proliferation in the SVZ following either dose of estradiol compared to the controls. Furthermore, 21 days after their generation in the SVZ, the number of BrdU labeled cells was also lower in the main $\mathrm{OB}$, both in the granular and periglomerular cell layers of estradiol-treated animals. These results show that a short term treatment with estradiol actually downregulates cell proliferation leading to a decreased number of newborn cells in the OB. () 2010 IBRO. Published by Elsevier Ltd. All rights reserved.
\end{abstract}

Key words: main olfactory bulb, cell proliferation, cell survival, 5-bromo-2-deoxyuridine, estrogens, female mice.

In mammals, constitutive neurogenesis mainly occurs in the adult brain in two regions: the subgranular zone (SGZ) of the hippocampal dentate gyrus (DG) and the olfactory

*Corresponding author. Tel: +32-4-366-59-78; fax: +32-4-366-59-53. E-mail: jbakker@ulg.ac.be (J. Bakker).

Abbreviations: AOB, accessory olfactory bulb; ArKO, aromatase knockout; DG, dentate gyrus; EB, estradiol-benzoate; GrL, granular cell layer; MOB, main olfactory bulb; OB, olfactory bulb; PgL, periglomerular cell layer; SGZ, subgranular zone; SVZ, subventricular zone. bulb (OB) (Zhao et al., 2008). Concerning olfactory neurogenesis, most cells born in the anterior portion of the subventricular zone (SVZ) give rise to neuroblasts that migrate along the rostral migratory stream (RMS) to the $\mathrm{OB}$, where they differentiate into functional granular and periglomerular olfactory interneurons (Lois and AlvarezBuylla, 1994). It has been shown, mostly with regard to neurogenesis in the DG, that cell proliferation as well as the survival of many newborn neurons are affected by a number of growth factors, neurotransmitters (Abrous et al., 2005) as well as steroid hormones (Brannvall et al., 2002; Lee et al., 2002; Perez-Martin et al., 2003; Mechawar et al., 2004; Suzuki et al., 2004; for review see: Galea et al., 2006; Galea, 2008; Pawluski et al., 2009). The most extensively studied neurosteroid in a variety of animal models is estradiol which has been shown to prevent cell death, promote neuronal survival, enhance neurite outgrowth, stimulate synaptogenesis and regulate synthesis of neurotransmitters and their receptors (Wise et al., 2001). In rodents, effects of estradiol on neurogenesis (cell proliferation and newborn cell survival) in the DG depend on the strain, gender, dose or regimen of hormone administration, timing of gonadectomy and age of the subjects (Galea and McEwen, 1999; Tanapat et al., 1999; Ormerod and Galea, 2001; Tanapat et al., 2005; Lagace et al., 2007; Barker and Galea, 2008; Galea, 2008). Surprisingly, the effects of steroid hormones on adult olfactory neurogenesis are relatively unknown (Abrous et al., 2005). Although estrogen action in the CNS is extensively studied, evidence is still lacking on its effect on neurogenesis in those brain areas that might be fundamental in regulating sexual behavior, such as regions related to olfaction (Gheusi et al., 2009). Moreover, as the ability to detect and to discriminate pheromones plays an important role in mate selection and in reproductively related events, it seems reasonable to hypothesize that hormones modulate neurogenesis in the SVZ and by consequence in the OB (Shingo et al., 2003). In this context, Mak et al. (2007) showed that male pheromones stimulated cell proliferation in the SVZ of adult female mice and also led to a higher rate of surviving newborn neurons in the OB. Furthermore, by using aromatase knockout (ArKO) male and female mice (which carry a targeted mutation in the aromatase gene and as a result cannot convert androgens to estrogens) or ER $\alpha \mathrm{KO}$ male mice (which lack estrogen receptors binding estradiol), it has been observed that these mice never showed a preference for an opposite-sex partner when tested in a Y-maze paradigm suggesting that estradiol might be important for mate recognition (Wersinger and Rissman, 
2000; Bakker et al., 2002, 2004). It can thus be hypothesized that estradiol could affect mate selection by a possible modulation of neurogenesis in the SVZ and by consequence the recruitment of newborn cells in the $\mathrm{OB}$ and hence olfactory discrimination. To date there have been two studies investigating the role of estradiol on neurogenesis in the OB of rodents (Hoyk et al., 2006; Suzuki et al., 2007). One study demonstrated that estradiol can act to decrease the number of newborn cells in the accessory OB (AOB) (Hoyk et al., 2006) and the other study found no effect of estradiol treatment on cell proliferation in the SVZ (Suzuki et al., 2007). However, Suzuki et al. (2007) used a very low dose of estradiol (equivalent to a diestrous state) and it is possible that higher levels of estradiol (equivalent to a proestrous state) may affect more efficiently the rate of olfactory neurogenesis.

Therefore, the aim of the present study was to determine whether estradiol would affect cell proliferation in the SVZ and subsequently the number of newborn neurons in the OB. As it was previously shown that different regimens of hormone replacement could lead to different effects on neurogenesis (Tanapat et al., 2005), we used two different approaches of estradiol treatment (a single injection vs. an implant of a Silastic capsule) to determine whether estradiol modulates cell proliferation in the SVZ and subsequently the number of newborn cells in the OB.

\section{EXPERIMENTAL PROCEDURES}

\section{Animals}

Two-month-old C57BI6/J female mice were obtained from a local breeding colony at the GIGA Neurosciences, University of Liège, Belgium. Subjects were housed in groups of four per cage, under a $12 \mathrm{~h}: 12 \mathrm{~h}$ light-dark cycle $(8.00 \mathrm{~h}$ lights on and $20.00 \mathrm{~h}$ lights off) in special light and temperature controlled housing units. Food and water were always available ad libitum.

All adult female mice were ovariectomized at the age of 9 weeks under general anesthesia after an i.p. injection of a mixture of ketamine (Pfizer, Brussels, Belgium, $80 \mathrm{mg} / \mathrm{kg}$ per mouse) and medetomidine (Domitor, Pfizer, Louvain-la-Neuve, Belgium, 1 $\mathrm{mg} / \mathrm{kg}$ per mouse). Mice received atipamezole (Antisedan, Pfizer, Brussels, Belgium, $4 \mathrm{mg} / \mathrm{kg}$ per mouse) s.c. at the end of the surgery in order to antagonize medetomidine-induced effects, thereby accelerating their recovery.

All experiments were conducted in accordance with the guidelines set forth by the National Institutes of Health "Guiding Principles for the Care and Use of Research Animals," and were approved by the Ethical Committees for Animal Use of the University of Liege. Effort was made to minimize the number of animals used and their suffering in this study.

\section{Estradiol treatment and BrdU administration}

Cell proliferation in the SVZ. Estradiol by single injection. One week after ovariectomy, adult female mice received either a single s.c. injection of 1 or $10 \mu \mathrm{g} 17 \beta$-estradiol [stock solution stored in a light-proof vial $=1 \mathrm{mg} 17 \beta$-estradiol (ICN Biomedicals Inc., Illkirch, France, CAT no. 101656) diluted in $10 \mathrm{ml}$ sesame oil (Sigma, Steinheim, Germany)] ( $n=7$ females for each injection condition), or oil ( $n=6$ females for vehicle injections). Two hours after the injection, subjects received a single i.p. injection of 5-bromo-2' -deoxyuridine (BrdU Ultra 99\%-Sigma B9285) at $50 \mathrm{mg} / \mathrm{kg}$ body weight (dissolved in $0.9 \%$ saline) and were killed $2 \mathrm{~h}$ later
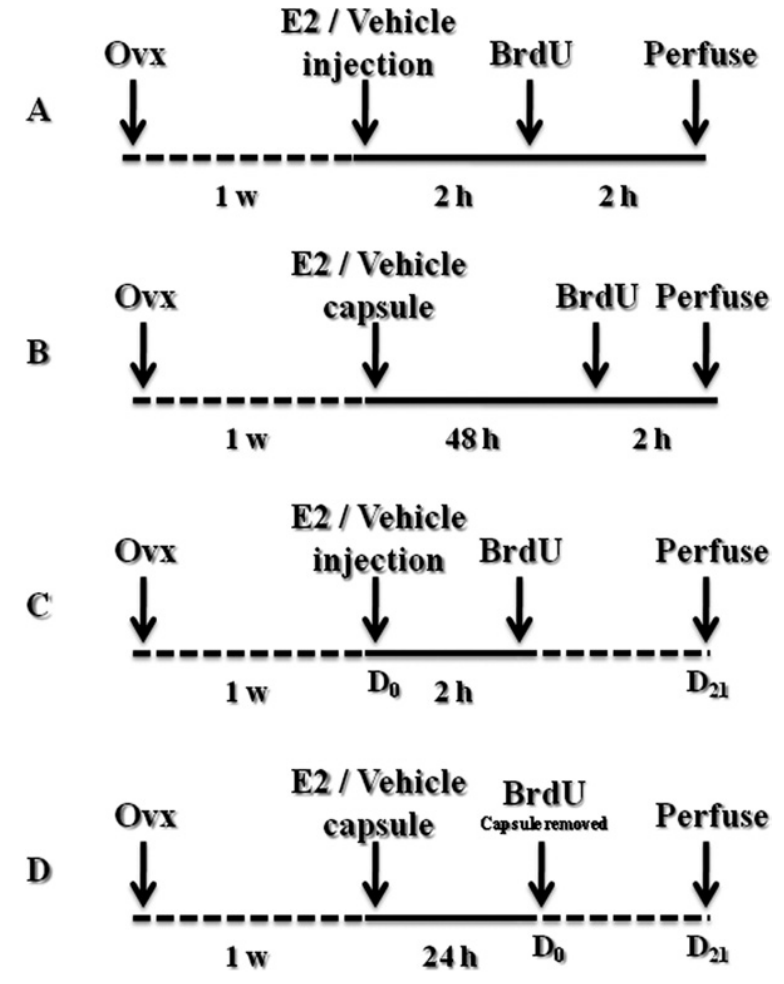

Fig. 1. Summary of the experimental design. For studying cell proliferation in the subventricular zone (SVZ), ovariectomized C57BI6/J females of 9 weeks of age received either a short term treatment with estradiol by either a single injection of 1 or $10 \mu \mathrm{g} 17 \beta$-estradiol (A) or a Silastic capsule containing crystalline $17 \beta$-estradiol (B), or oil (or empty implant). In the single estradiol injection protocol (A), mice received a single i.p. injection with BrdU $(50 \mathrm{mg} / \mathrm{kg}) 2 \mathrm{~h}$ after estradiol injection and were perfused with $4 \%$ paraformaldehyde $2 \mathrm{~h}$ after BrdU administration. In the estradiol implant protocol (B), mice received a single i.p. injection with BrdU $48 \mathrm{~h}$ after being implanted and were perfused $2 \mathrm{~h}$ after BrdU administration. For studying newborn cell survival in the $\mathrm{OB}$, ovariectomized females received a short term treatment with estradiol by either a single injection of $10 \mu \mathrm{g} 17 \beta$ estradiol (C) or a Silastic capsule containing crystalline $17 \beta$-estradiol (D), or oil (or empty implant). In the single injection protocol (C), mice received four i.p. injections with BrdU ( $2 \mathrm{~h}$ intervals) $2 \mathrm{~h}$ after estradiol injection $\left(D_{0}\right)$ and were perfused 21 days later $\left(D_{21}\right)$. In the estradiol implant protocol, mice received four i.p. injections with BrdU ( $2 \mathrm{~h}$ intervals) $24 \mathrm{~h}$ after the capsule was implanted. The implant was removed $3 \mathrm{~h}$ after the last BrdU injection $\left(D_{0}\right)$ and mice were perfused 21 days later $\left(D_{21}\right)$.

(Fig. 1A). At this time period, BrdU labels dividing progenitor cells only (Conover and Allen, 2002).

Estradiol by silastic implant. One week after ovariectomy, adult female mice received either a short term treatment with a s.c. Silastic capsule containing crystalline 17 $\beta$-estradiol [diluted 1:1 with cholesterol (Sigma)] during $48 \mathrm{~h}$ ( $n=8$ females), or an empty caspule ( $n=8$ females). These capsules provide estrous levels of estradiol (for more details see Bakker et al., 2002). Estradiol capsules were put in saline at $37{ }^{\circ} \mathrm{C}$ during $24 \mathrm{~h}$ before being implanted in order to initiate the diffusion of the steroid, so at the time of implantation, the implants have started releasing the steroid. Two days later, subjects received a single i.p. injection of BrdU and were killed $2 \mathrm{~h}$ later (Fig. 1B).

Cell survival in the $O B$. Estradiol by single injection. One week after ovariectomy, adult female mice received a single s.c. injection of $10 \mu \mathrm{g} 17 \beta$-estradiol $(n=7)$ or oil $(n=5)$ at $9.00 \mathrm{~h}$. Two hours after the injection, subjects received an i.p. injection with 
BrdU $(50 \mathrm{mg} / \mathrm{kg}$ ) four times with $2 \mathrm{~h}$ intervals (between $11.00 \mathrm{~h}$ and $18.00 \mathrm{~h}$ ) and were killed 21 days later (Fig. 1C). At this time period, BrdU labels newly generated cells in the SVZ and which have migrated to the $\mathrm{OB}$ and have been differentiated into mature granule cells and periglomerular cells (Petreanu and AlvarezBuylla, 2002). In order to analyze the cell survival in the OB, we used a classical protocol of BrdU injection for analyzing cell survival in the $O B$ which requires more BrdU (a minimum of four injections) compared to cell proliferation studies in the SVZ in which only one or two injections of BrdU are sufficient (Rochefort et al., 2002; Veyrac et al., 2009).

Estradiol by silastic implant. One week after ovariectomy, adult female mice received either a short term treatment with a s.c. Silastic capsule containing crystalline $17 \beta$-estradiol $(n=8)$, or an empty caspule $(n=5)$. Twenty-four hours after the capsule was implanted, subjects received an i.p. injection with BrdU $(50 \mathrm{mg} / \mathrm{kg})$ four times with $2 \mathrm{~h}$ intervals (between $11.00 \mathrm{~h}$ and $18.00 \mathrm{~h}$ ). In order to minimize interferences between surgery and BrdU cell incorporation, the capsule was removed $3 \mathrm{~h}$ after the last BrdU injection (BrdU is generally considered to be bioactive in vivo for about $2 \mathrm{~h}$ following an i.p. injection; Steiner et al., 2008). All animals were killed 21 days later (Fig. 1D). Estradiol capsules were preincubated in saline at $37^{\circ} \mathrm{C}$ to ensure immediate diffusion of the steroid upon implantation.

At the end of each experiment, animals were anesthetized and perfused transcardially with saline followed immediately by $4 \%$ cold paraformaldehyde. Brains were removed and postfixed in $4 \%$ paraformaldehyde for $2 \mathrm{~h}$. Then brains were cryoprotected in $30 \%$ sucrose/PBS solution and when sunken, frozen on dry ice and stored at $-80{ }^{\circ} \mathrm{C}$. Forebrains were cut coronally on a Leica CM3050S cryostat from the beginning of the OB (sections of 20 $\mu \mathrm{m}$ ) to the level of SVZ (sections of $30 \mu \mathrm{m}$ ). Serial sections were stored at $-20{ }^{\circ} \mathrm{C}$ for later immunohistochemistry.

\section{Immunohistochemistry}

Cell proliferation study. All incubations of free floating sections were carried out at room temperature $\left(22^{\circ} \mathrm{C}\right)$ and all washes of brain tissue sections were performed using phosphate-buffered saline (PBS $0.01 \mathrm{M}$ ) or phospate-buffered saline containing $0.2 \%$ Triton X-100 (PBST). Endogenous peroxidase activity was quenched by incubating the sections for 20 min with $0.6 \%$ hydrogen peroxide. To ensure access of antibody to BrdU containing DNA chains, sections were incubated for $20 \mathrm{~min}$ at $37^{\circ} \mathrm{C}$ with $2 \mathrm{~N}$ $\mathrm{HCl}$. To restore the $\mathrm{pH}$, sections were rinsed for 10 min with borate buffer (0.1 $\mathrm{M}-\mathrm{pH}=8.5)$. Aspecific binding sites were blocked by incubating sections for 30 min with $10 \%$ normal donkey serum (Jackson ImmunoResearch) and PBST. Sections were then incubated with rat anti-BrdU antibody (1/400 in PBST; OBT0030ABD Serotec) overnight at $4{ }^{\circ} \mathrm{C}$. Then, sections were incubated for $2 \mathrm{~h}$ with a donkey anti-rat biotinylated antibody (1/2000 in PBST; Jackson ImmunoResearch). Sections were then processed for 90 min in avidin-biotin complex (ABC, Vector Laboratory) and rinsed in PBST. Sections were reacted for $10 \mathrm{~min}$ in a PBS solution containing $0.012 \% \mathrm{H}_{2} \mathrm{O}_{2}$ and $0.05 \%$ diaminobenzidine. Sections were then washed, mounted onto gelatin-coated slices, dried overnight, left in xylene (Sigma) for 15 min and coverslipped using Eukit (Fluka).

Cell survival study in the $O B$. In order to keep the exact order of the sections from the $\mathrm{OB}$ and to facilitate stereological analysis of the BrdU signal, we mounted sections directly onto slides. All OB sections were processed for BrdU immunoreactivity as was previously described (Veyrac et al., 2009) and we ensured that this BrdU labelling method was comparable in free floating or mounted sections for the same brain region (data not shown). All incubations were carried out at room temperature $\left(22^{\circ} \mathrm{C}\right)$ and all washes of brain tissue sections were performed using phosphatebuffered saline (PBS $0.01 \mathrm{M}$ ) or phospate-buffered saline contain- ing $0.5 \%$ Triton $\mathrm{X}-100$ (PBST). To ensure access of antibody to BrdU, sections were incubated for $20 \mathrm{~min}$ at $98^{\circ} \mathrm{C}$ with a Dako solution (Target Retrieval Solution-Dako Cytomation). After cooling for $20 \mathrm{~min}$, sections were incubated for 3 min with $1 \mathrm{~N} \mathrm{HCl}$ and $0.0125 \%$ pepsine (Sigma). To eliminate endogenous peroxidase activity, sections were incubated for 30 min with $3 \% \mathrm{H}_{2} \mathrm{O}_{2}$. Aspecific binding sites were blocked by incubating sections for $90 \mathrm{~min}$ with 5\% normal horse serum (Jackson ImmunoResearch) and 5\% BSA (Sigma) in PBST. Sections were then incubated with mouse anti-BrdU antibody (1/100 in PBST; Chemicon, Millipore) overnight at $4{ }^{\circ} \mathrm{C}$. Then, sections were incubated for $2 \mathrm{~h}$ with a horse anti-mouse biotinylated antibody (1/200 in PBST; Vector). Sections were then processed for $30 \mathrm{~min}$ in avidin-biotin complex (ABC, Vector Laboratory) and rinsed in PBS. Sections were then preincubated for 5 min with $0.06 \%$ DAB solution (Sigma). Sections were reacted for $5 \mathrm{~min}$ in a Tris solution containing $0.03 \% \mathrm{NiCl}_{2}$, $0.03 \% \mathrm{H}_{2} \mathrm{O}_{2}$ and $0.06 \%$ DAB. Sections were then washed, dried overnight, left in xylene (Sigma) for $15 \mathrm{~min}$ and coverslipped using Eukit (Fluka, Steinheim, Germany).

\section{BrdU-stained nuclei quantification}

A Zeiss microscope coupled with a computer-assisted image analysis system (Mercator Pro; Explora Nova, La Rochelle, France) was used for quantifying BrdU labeling. Cell counts and area measurements were performed using a previously validated method (Petreanu and Alvarez-Buylla, 2002; Veyrac et al., 2005). For each OB section, the granular cell layer ( $\mathrm{GL}$ ), the periglomerular cell layer $(\mathrm{PgL})$ and the subendymal cell layer (SEL-OB) were delineated using a $5 \times$ objective. All BrdU positive nuclei were counted in the GrL and PgL using a $20 \times$ objective in four sections at $600 \mu \mathrm{m}$ intervals, starting from the anterior main OB (MOB) to the rostral apex of the AOB. The SVZ was delineated using a $5 \times$ objective based on the histological difference from the surrounding tissue around the lateral ventricle and all labeled BrdU-positive cells were counted using a $20 \times$ objective in four sections per animal starting from the opening of the ventricle (intersection intervals of $360 \mu \mathrm{m}$ ). The volume of each layer was calculated according to a classical stereological method (Howard and Reed, 1998), using the area of each section, the distance between traced sections and the total number of sections. Profile density (number of labeled cell outlines $/ \mu \mathrm{m}^{2}$ on sections) and number density (number of labeled cell $/ \mu \mathrm{m}^{3}$ ) were derived from these data. The total number of cells $(T)$ was estimated using the formula:

$$
T=(N \times V) / t
$$

with $V$ being the volume, $N$ the profile density (number of profiles/ $\mu \mathrm{m}^{2}$ ) and $t$ the thickness of the sections. $T$ was then related to the volume of the region of interest, to express data as a number of cells per $\mathrm{mm}^{3}$ (volumetric density).

\section{Statistics}

The data were averaged across animals within each experimental group (estradiol-treated vs. vehicle-treated) and statistical differences were assessed using one-way analysis of variance (ANOVA; Statistica 8.0) followed by Fisher post hoc tests for experiments with more than two groups. For experiments consisting of only two groups, we used a two-tailed Student's $t$-test.

\section{RESULTS}

\section{Cell proliferation in the SVZ}

A short term treatment with estradiol led to a significant decrease in cell proliferation in the SVZ following either regimen of estradiol administration as compared to controls. 
A

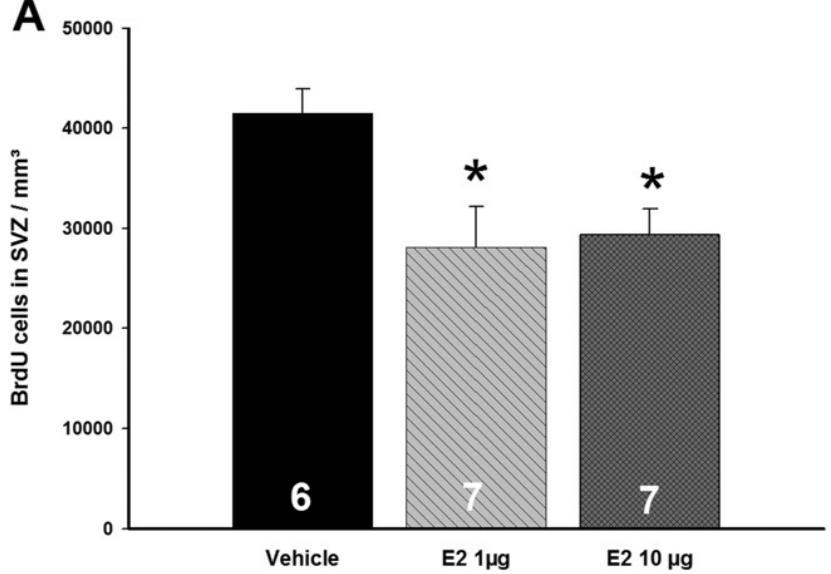

B

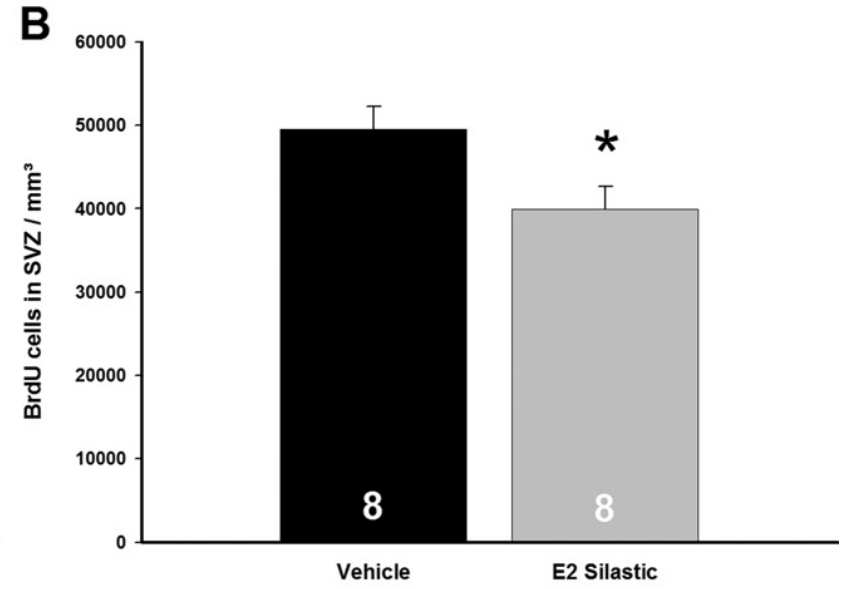

Fig. 2. Effects of estradiol on cell proliferation. Mean \pm SEM total number of BrdU cells in the SVZ following either a single injection of 1 or $10 \mu \mathrm{g}$ $17 \beta$-estradiol (A) or a an implant with a Silastic capsule containing crystalline $17 \beta$-estradiol (B), or oil/empty implant (vehicle conditions). The number of subjects is indicated in the bars. ${ }^{*} P<0.05$ post hoc comparisons between estradiol and vehicle treatments.

Estradiol by single injection. ANOVA on the number of BrdU cells in the SVZ showed a significant effect of treatment $(F(2,17)=5.01, P=0.019)$. Post hoc analysis showed that a single injection of $\mathrm{E} 2$, either $1 \mu \mathrm{g}(P=0.01)$ or $10 \mu \mathrm{g}$ $(P=0.02)$, led to a $30 \%$ decrease of BrdU labelled cells in the SVZ compared to a single injection with vehicle (Fig. 2A). Representative photomicrographs are shown in Fig. 3A-C.
Estradiol by silastic implant. T-test on the number of BrdU cells in the SVZ showed a significant difference between estradiol and vehicle treatments $\left(t_{(14)}=2.50\right.$, $P=0.025)$. When delivering estrous levels of estradiol using the silastic implant, we also observed a $19 \%$ decrease of cell proliferation in the SVZ (Fig. 2B). Representative photomicrographs are shown in Fig. 3D, E.

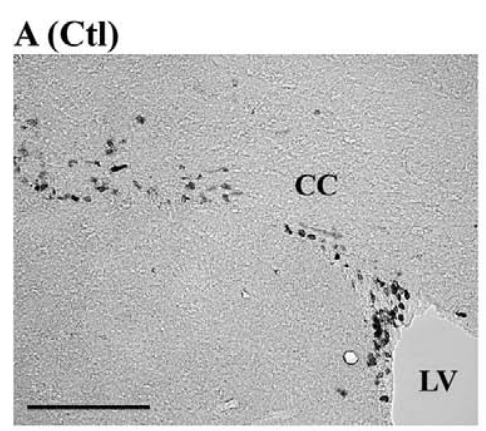

D (Ctl)

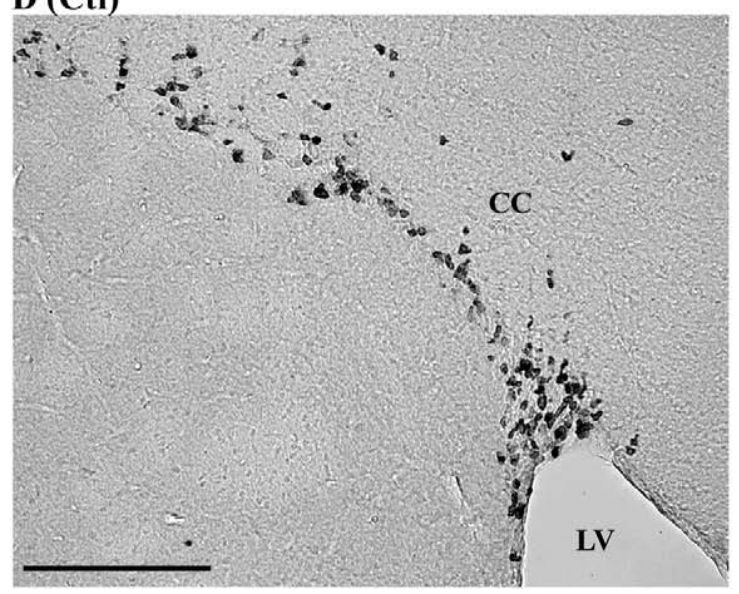

\section{B (E2 1 $\mu \mathrm{g})$}

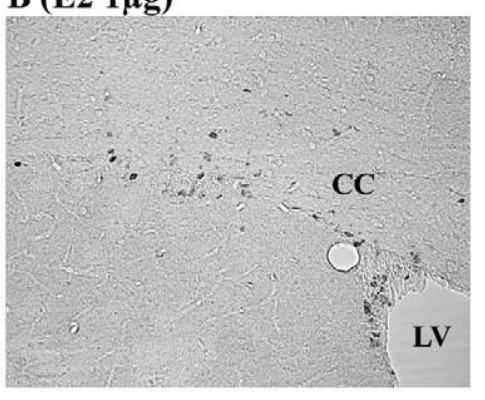

E (E2 capsule)

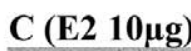

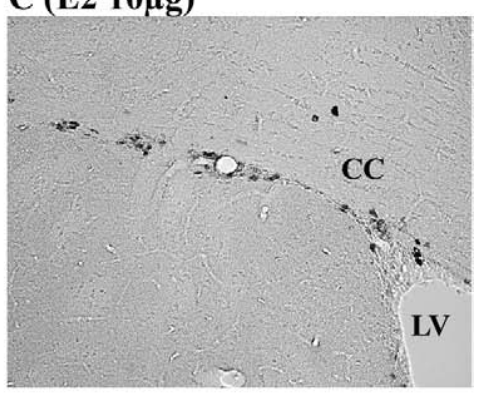

LV

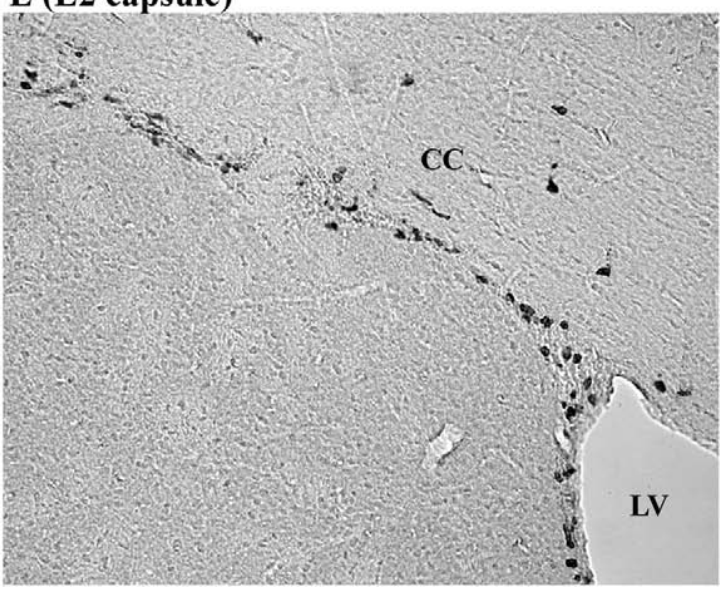

Fig. 3. Representative photomicrographs of 5-bromo-2 deoxyuridine (BrdU)-immunopositive cells in the subventricular zone (A-E). Number of cells incorporating BrdU was decreased in estradiol-treated mice (E2 $1 \mu \mathrm{g}$, E2 $10 \mu \mathrm{g}$ and E2 capsule) compared to vehicle-treated control mice (CtI) in the SVZ (A-E). Abbreviations: LV, lateral ventricle; CC, corpus callosum. Scale bars $=150 \mu \mathrm{m}(\mathrm{A}-\mathrm{E})$. 

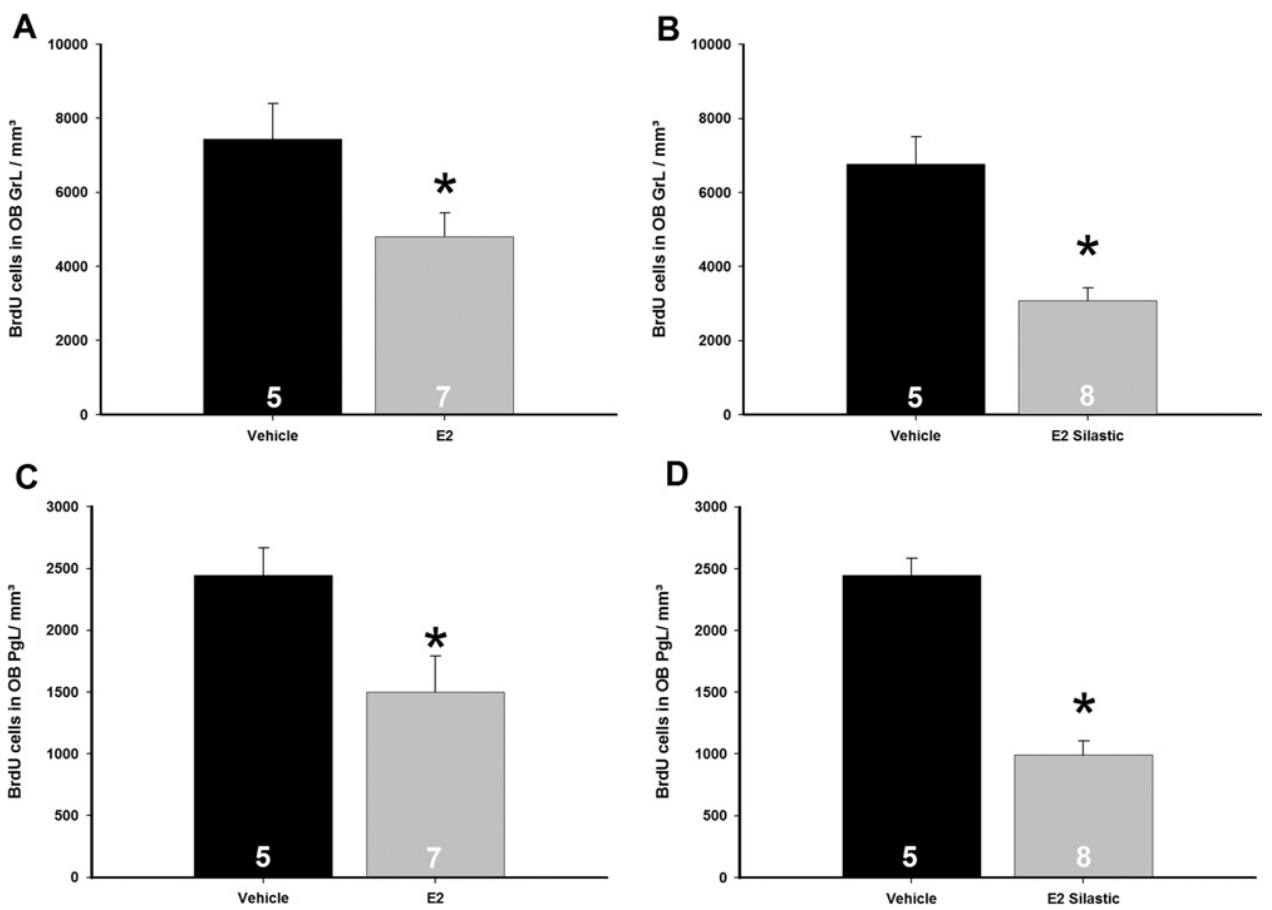

Fig. 4. Effects of estradiol on cell survival. Mean \pm SEM total number of BrdU cells in the granular layer $(A, B)$ and periglomerular layer (C, D) in the olfactory bulb following a short term treatment with estradiol by either a single injection of $10 \mu \mathrm{g} 17 \beta$-estradiol $(\mathrm{A}, \mathrm{C}$ ) or by a Silastic capsule containing crystalline $17 \beta$-estradiol (B, D), or oil/empty implant (vehicle conditions). The number of subjects is indicated in the bars. ${ }^{*} P<0.05$ between estradiol and vehicle treatments.

\section{Cell survival in the OB}

The decrease observed in cell proliferation in the SVZ induced by a short term treatment with estradiol also led to a decreased number of newly generated granular and periglomerular cells in the OB.

Estradiol by single injection. T-tests on the number of BrdU cells in the GrL of the OB showed a significant difference between estradiol and vehicle injections $\left(t_{(10)}=2.39, P=0.038\right)$. Estradiol treatment led to a $35 \%$ decrease of newborn cells integrated into the GrL of the $\mathrm{OB}$ (Fig. 4A) whereas the volume of the GrL did not change compared to the vehicle condition (data not shown). $T$-tests on the number of BrdU cells in the PgL of the $\mathrm{OB}$ also showed a significant difference between estradiol and vehicle injections $\left(t_{(10)}=2.39, P=0.038\right)$. Estradiol treatment led to a $39 \%$ decrease of newborn cells integrated into the PgL of the $\mathrm{OB}$ (Fig. 4C) whereas the volume of the $\mathrm{PgL}$ did not change compared to the vehicle condition (data not shown). These results suggest that cells destined to the granular and periglomerular cell layers in the $\mathrm{OB}$ responded in a similar fashion to the short term treatment with estradiol. Representative photomicrographs are shown in Fig. 5A, 5B.

Estradiol by silastic implant. Very similar results were obtained when estradiol was administered by silastic implant. Thus $T$-tests on the number of BrdU cells in the GrL and the PgL of the $\mathrm{OB}$ showed a significant difference between estradiol and vehicle treatments $\left(\mathrm{GrL}: t_{(11)}=5.19\right.$, $P=0.0003$; PgL: $\left.t_{(11)}=7.96, P<0.0001\right)$. Estradiol treat- ment led to a $54 \%$ and $60 \%$ decrease of newborn cells integrated into the $\mathrm{GrL}$ and the PgL, (Fig. 4B, 4D), respectively, whereas their volumes did not change compared to the vehicle condition (data not shown). Representative photomicrographs are shown in Fig. 5C, 5D.

\section{DISCUSSION}

Our results demonstrate that estradiol downregulates cell proliferation in the SVZ leading to a decreased number of newborn cells in adult female mice $O B$. Since the volumes of the granular layer and the periglomerular layer of the $O B$ did not vary following estradiol treatment, it clearly suggests that estradiol acts on cell proliferation and the subsequent cell survival in the OB without affecting apoptosis of preexisting neurons in the $\mathrm{OB}$ (Petreanu and AlvarezBuylla, 2002).

It has been suggested that estradiol plays a role in cell proliferation in the OB. For instance, estradiol stimulates neurogenesis in the adult SVZ following ischemic stroke in mice, thus potentially facilitating brain repair after injury (Suzuki et al., 2007). In this latter experiment, estradiol had no effect on cell proliferation in uninjured subjects when uncontrolled proliferation might not be desirable; however, the authors used very low doses of estradiol equivalent to low-basal circulating levels found during the diestrous state in female mice (Nelson et al., 1992) compared to our study using doses of estradiol corresponding to an estrous state. Smith et al. (2001) showed that exposure of female prairie voles to a male induced behavioral estrus and an increase in proliferation of BrdU-labelled cells from the 

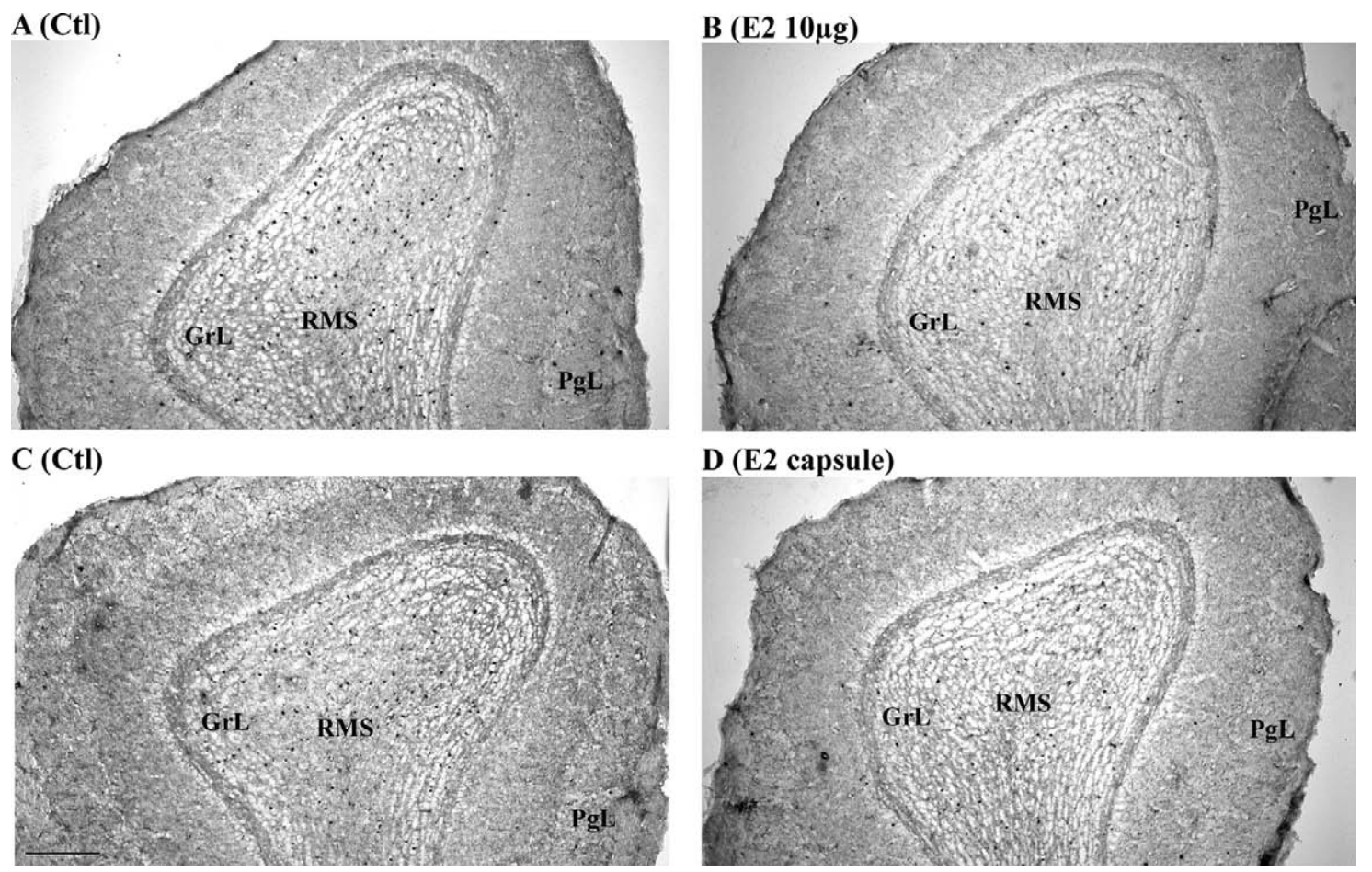

Fig. 5. Representative photomicrographs of 5-bromo-2 deoxyuridine (BrdU)-immunopositive cells in the olfactory bulb (A-D). Number of cells incorporating BrdU was decreased in estradiol-treated mice [E2 $10 \mu \mathrm{g}(\mathrm{B})$ and E2 capsule (D)] compared to vehicle-treated control mice (Ctl-A, C) in the OB. Abbreviations: GrL, granular cell layer; PgL, periglomerular cell layer; RMS, rostral migratory system. Scale bar=200 $\mu \mathrm{m}$ (A-D).

SVZ to the subependymal zone of the OB. As no proliferation was observed in ovariectomized females exposed to a sexual partner as well as the observation that estradiolbenzoate $(E B)$ treatment was sufficient to restore the increased production of neuronal progenitors in the SVZ in ovariectomized females, they suggested that estradiol was partly involved in the stimulation of proliferation of SVZderived neuroblasts. However, they did not analyze whether these stimulatory effects of EB on cell proliferation in the SVZ was actually accompanied with an increase in newly generated cells in the RMS and the OB. Nevertheless, their results showed some stimulatory effects of EB on cell proliferation in the SVZ whereas we observed a decrease in cell proliferation in the SVZ following estradiol treatment. These discrepancies might be due to species differences, since female prairie voles seem to rely on male pheromonal cues to get into behavioral estrus, which is obviously not the case in mice. Thus it is possible that estrus induction and thus increased olfactory neurogenesis is accompanied by other, non specified, hormonal changes in the female prairie vole. Furthermore, there are some other differences between our and their study, like different timing following ovariectomy, different forms of estradiol used, different injection protocols for estradiol and BrdU. Only one study has suggested that estradiol affects cell survival in the OB: Hoyk et al. (2006) showed that an estrogen treatment for 6 days decreased the survival rate of newly integrated interneurons in the $O B$ of adult female rats. Surprisingly, they only observed a decrease in cell survival in the AOB and not in the MOB. However, this study did not analyze any effects of estradiol on cell proliferation in the SVZ. Thus it cannot be determined whether the decrease observed in the AOB resulted from either a decrease in the number of newborn cells generated in the SVZ or from a specific negative effect of estradiol in the survival of granule and periglomerular cells of the OB.

Continuous adult neurogenesis is required for the maintenance and reorganization of the whole interneuron system into the $\mathrm{OB}$, and thus may play an important role in the modulation of processing of sensory information by interaction between the newborn granular and periglomerular cells and their olfactory bulb's projection neurons, the mitral and tufted cells (Lledo et al., 2006; Mouret et al., 2009). This brain plasticity seems to be crucial to the onset of several behaviors since several studies highlight strong correlations between the rate of newborn neurons survival in the $\mathrm{OB}$ and their possible implications in olfactory discrimination (Gheusi et al., 2009), odor memory (Rochefort et al., 2002) and olfactory learning (Mouret et al., 2008). However, it should be noted that the exact physiological role of "olfactory neurogenesis" remains unknown. In the $\mathrm{OB}$, many studies suggest that newly integrated neurons may contribute to the perceptual and "memory" functions of the bulb, sometimes associated with social behavior (Gheusi et al., 2009). Exposure to male pheromones advances maternal behavior in female mice; this pheromone action is dependent on ovarian steroids and peptide hormones (especially prolactin), and is associated with increased cell proliferation in the SVZ during pregnancy and lactation (Shingo et al., 2003) and subsequent increase in new neurons in the $\mathrm{OB}$ leading to a better recognition of 
pups and thus an advanced maternal behavior (Lennington et al., 2003; Larsen et al., 2008). Ovariectomy suppressed this increased cell proliferation and by consequence the advanced maternal behavior suggesting thus that estradiol could partly be involved in this effect. Mak et al. (2007) showed that dominant, but not subordinate, male pheromones provided specific sensory stimuli that stimulate proliferation in the SVZ of adult female mice and also led to a higher rate of newborn neurons in the OB. They showed that prolactin receptors mediate the increased production of neuroblasts in the SVZ however, they did not determine the role of estradiol on these effects. Mak et al. (2007) also suggested that LH might play a role in stimulating cell proliferation in the SVZ: administration of $\mathrm{LH}$ increased cell proliferation in the SVZ but only when using very high doses of LH. However, when they decreased their dose to $10 \%$ of the original dose they no longer observed an effect of $\mathrm{LH}$ infusion on cell proliferation in the SVZ. Although we did not measure LH levels in our mice, we can safely assume that $\mathrm{LH}$ levels were much lower than those that resulted of the $\mathrm{LH}$ treatment in the study by Mak et al. (2007). Furthermore, whether LH actually plays a role in the brain itself is still a subject of debate. A study by Pakarainen et al. (2005) showed that transplantation of wild-type ovary in luteinizing hormone receptor-knockout mice which were thus completely deprived of $\mathrm{LH}$ receptors completely restored their reproductive functions. This suggests that if there is any role for brain LH receptors in reproductive behavioral and sensory functions, it can only be minor. Finally, Mak et al. (2007) showed that dominant male pheromone-stimulated neurogenesis was required for mate selection in adult female mice, offering thus an ethological relevant function to adult female neurogenesis in the context of mate selection. As female prairie voles showed enhanced neurogenesis in the SVZ following exposure to males too and are a highly social species that form enduring selective pair bonds after mating (Smith et al., 2001), it would be interesting to examine whether this estrogen-mediated neurogenesis may play a role in the trace memory acquisition of the identity of the sexual partner. In male hamsters, Huang and Bittman (2002) showed that newborn cells integrated in the OB were specifically activated by exposure to an estrous female since they found an overlap between BrdU- and Fos-labelled cells. As the $O B$ is part of the brain circuit controlling sexual behavior, it is quite likely that gonadal hormones may influence sexual behavior through modulating neurogenesis in the OB.

With regard to possible contribution of continuous neurogenesis in social behaviors like sexual behavior or partner preferences, we previously observed that female ArKO mice (which cannot convert testosterone to estradiol) showed an enhanced ability to discriminate very similar urinary odorants in an olfactometer task (Wesson et al., 2006). As ArKO females were treated with EB during the olfactory discrimination tests, we first hypothesized that they presented a hypersensitivity to estradiol due to greater numbers of estrogen receptors (Kudwa et al., 2007). This hypersensitivity to estradiol could have induced a better in- tegration of new neurons in the $\mathrm{OB}$, and thus promote their abilities to discriminate very similar sexual attractants. However, our present study showed that estradiol decreases the rate of newly generated cells, and thus contradicts our previous hypothesis. We are currently studying the effects of estradiol on the "olfactory neurogenesis" in adult female ArKO mice to better understand their olfactory performances.

As the majority (75-99\%) of the newborn cells that are going to be integrated in the $\mathrm{OB}$ are GABA-ergic and thus inhibitory (Mouret et al., 2009), we could also suggest that in state of estrus there could be a decrease of inhibitory influences on olfaction which could facilitate the integration of pheromonal cues and by consequence the discrimination between different subtle odors. However, this hypothesis contradicts current observations showing that pharmacological blockade of GABAergic inhibition impairs discrimination between closely related odorants (Stopfer et al., 1997). Moreover, it has been shown that, through inhibition, granule cell activity enhances the refinement of odor-molecule tuning by the synchronization of mitral cell subpopulations widely distributed in the OB (for review see Kay et al., 2009).

We thus suggest that estradiol could act as a potential regulator of cell proliferation in the subventricular zone and subsequently the rate of newly generated cells in the $\mathrm{OB}$ and thus could modulate the processing of olfactory cues that are important for socio-sexual behaviors. Moreover, the cyclical fluctuations in sex hormone levels raise the possibility of corresponding cyclical waves of neurogenesis leading perhaps to a better integration of pheromonal information and thus facilitating reproduction. For example, during proestrus, a time when estrogen levels are high, cell proliferation in the SGZ of the hippocampus increases, compared with estrus and diestrus, when estrogens levels are lower (Tanapat et al., 1999). Clear evidence is still lacking about the effects of estradiol in the SVZ, but our study suggests an opposite way of action of estradiol in the SVZ and in the OB compared to its effects in the DG of rodents. In the DG, it has been shown that estradiol stimulates cell proliferation within a few hours after exposure (Tanapat et al., 1999), which is in contrast to what we observed in the SVZ following a single injection of estradiol. However, a $48 \mathrm{~h}$ exposure to estradiol suppresses cell proliferation in the DG (Ormerod and Galea, 2001), which is in line with what we observed using silastic implants. It has been shown that the stimulatory effects of estradiol on cell proliferation in the SGZ were exerted directly on the progenitors via estrogen receptors $\alpha$ and $\beta$ (Nagy et al., 2006; Mazzucco et al., 2006) or indirectly by serotonin (Banasr et al., 2001; Shingo et al., 2003). Surprisingly, no estradiol receptors (ER $\alpha$ or $\mathrm{ER} \beta$ ) are found in the SVZ in mice (Mitra et al., 2003; Merchenthaler et al., 2004) although Isgor and Watson (2005) showed that Ki-67-immunoreactive cells of the SVZ expressed estrogen receptor alpha mRNA in rats. We thus suggest that estradiol most likely modulates cell proliferation by indirect pathways projecting to the SVZ such as dopamine $\beta$-hydroxylase (DBH) or tyrosine hydroxylase $(\mathrm{TH})$ neurons which are estradiol- 
sensitive (Temel et al., 2002; Kishi et al., 2005) or by GPR30 which are membrane receptors binding estradiol (Bologa et al., 2006). Several reports suggested that GPR30 might be a G-protein coupled estrogen receptor mediating nongenomic effects of estradiol but its brain localization and its exact role remain still unknown (Micevych and Dominguez, 2009; Micevych et al., 2009).

Acknowledgments-This work was supported by the following grants: the NICHD (HD044897), the University of Liège (C-06/89 and C-08/53), and the Fonds National de la Recherche Scientifique (FNRS; F 2.4572.09 with support of the French Community Wallonie-Brussels and the National lotery), all to Dr. Bakker. Dr. Bakker is a research associate of the FNRS. Dr. Keller is a research associate at the CNRS. We also thank Dr. Jodi Pawluski for commenting on an earlier version of the manuscript.

\section{REFERENCES}

Abrous DN, Koehl M, Le Moal M (2005) Adult neurogenesis: from precursors to network and physiology. Physiol Rev 85:523-569.

Bakker J, Honda S, Harada N, Balthazart J (2002) The aromatase knock-out mouse provides new evidence that estradiol is required during development in the female for the expression of sociosexual behaviors in adulthood. J Neurosci 22:9104-9112.

Bakker J, Honda S, Harada N, Balthazart J (2004) Restoration of male sexual behavior by adult exogenous estrogens in male aromatase knockout mice. Horm Behav 46:1-10.

Banasr M, Hery M, Brezun JM, Daszuta A (2001) Serotonin mediates oestrogen stimulation of cell proliferation in the adult dentate gyrus. Eur J Neurosci 14:1417-1424

Barker JM, Galea LA (2008) Repeated estradiol administration alters different aspects of neurogenesis and cell death in the hippocampus of female, but not male, rats. Neuroscience 152:888-902.

Bologa CG, Revankar CM, Young SM, Edwards BS, Arterburn JB, Kiselyov AS, Parker MA, Tkachenko SE, Savchuck NP, Sklar LA, Oprea TI, Prossnitz ER (2006) Virtual and biomolecular screening converge on a selective agonist for GPR30. Nat Chem Biol 2:207-212.

Brannvall K, Korhonen L, Lindholm D (2002) Estrogen-receptor-dependent regulation of neural stem cell proliferation and differentiation. Mol Cell Neurosci 21:512-520.

Conover JC, Allen RL (2002) The subventricular zone: new molecular and cellular developments. Cell Mol Life Sci 59:2128-2135.

Galea LA (2008) Gonadal hormone modulation of neurogenesis in the dentate gyrus of adult male and female rodents. Brain Res Rev 57:332-341.

Galea LA, McEwen BS (1999) Sex and seasonal differences in the rate of cell proliferation in the dentate gyrus of adult wild meadow voles. Neuroscience 89:955-964.

Galea LA, Spritzer MD, Barker JM, Pawluski JL (2006) Gonadal hormone modulation of hippocampal neurogenesis in the adult. Hippocampus 16:225-232.

Gheusi G, Ortega-Perez I, Murray K, Lledo PM (2009) A niche for adult neurogenesis in social behavior. Behav Brain Res 200:315-322.

Howard C, Reed M (1998) Unbiaised stereology: three-dimensional measurement in microscopy. Oxford, UK: Bios Scientific.

Hoyk Z, Varga C, Parducz A (2006) Estrogen-induced region specific decrease in the density of 5-bromo-2-deoxyuridine-labeled cells in the olfactory bulb of adult female rats. Neuroscience 141:1919 1924.

Huang L, Bittman EL (2002) Olfactory bulb cells generated in adult male golden hamsters are specifically activated by exposure to estrous females. Horm Behav 41:343-350.

Isgor C, Watson SJ (2005) Estrogen receptor alpha and beta mRNA expressions by proliferating and differentiating cells in the adult rat dentate gyrus and subventricular zone. Neuroscience 134 847-856.

Kay LM, Beshel J, Brea J, Martin C, Rojas-Libano D, Kopell N (2009) Olfactory oscillations: the what, how and what for. Trends Neurosci 32:207-214

Kishi Y, Takahashi J, Koyanagi M, Morizane A, Okamoto Y, Horiguchi S, Tashiro K, Honjo T, Fujii S, Hashimoto N (2005) Estrogen promotes differentiation and survival of dopaminergic neurons derived from human neural stem cells. J Neurosci Res 79:279-286.

Kudwa AE, Harada N, Honda SI, Rissman EF (2007) Effects of organisational oestradiol on adult immunoreactive oestrogen receptors (alpha and beta) in the male mouse brain. J Neuroendocrinol 19:767-772.

Lagace DC, Fischer SJ, Eisch AJ (2007) Gender and endogenous levels of estradiol do not influence adult hippocampal neurogenesis in mice. Hippocampus 17:175-180.

Larsen CM, Kokay IC, Grattan DR (2008) Male pheromones initiate prolactin-induced neurogenesis and advance maternal behavior in female mice. Horm Behav 53:509-517.

Lee J, Duan W, Mattson MP (2002) Evidence that brain-derived neurotrophic factor is required for basal neurogenesis and mediates, in part, the enhancement of neurogenesis by dietary restriction in the hippocampus of adult mice. J Neurochem 82:1367-1375.

Lennington JB, Yang Z, Conover JC (2003) Neural stem cells and the regulation of adult neurogenesis. Reprod Biol Endocrinol 1:99.

Lledo PM, Alonso M, Grubb MS (2006) Adult neurogenesis and functional plasticity in neuronal circuits. Nat Rev Neurosci 7:179-193.

Lois C, Alvarez-Buylla A (1994) Long-distance neuronal migration in the adult mammalian brain. Science 264:1145-1148.

Mak GK, Enwere EK, Gregg C, Pakarainen T, Poutanen M, Huhtaniemi I, Weiss S (2007) Male pheromone-stimulated neurogenesis in the adult female brain: possible role in mating behavior. Nat Neurosci 10:1003-1011.

Mazzucco CA, Lieblich SE, Bingham BI, Williamson MA, Viau V, Galea LA (2006) Both estrogen receptor $\alpha$ and estrogen receptor $\beta$ agonists enhance cell proliferation in the dentate gyrus of adult female rats. Neuroscience 141:1793-1800.

Mechawar N, Saghatelyan A, Grailhe R, Scoriels L, Gheusi G, Gabellec MM, Lledo PM, Changeux JP (2004) Nicotinic receptors regulate the survival of newborn neurons in the adult olfactory bulb. Proc Natl Acad Sci U S A 101:9822-9826.

Merchenthaler I, Lane MV, Numan S, Dellovade TL (2004) Distribution of estrogen receptor alpha and beta in the mouse central nervous system: in vivo autoradiographic and immunocytochemical analyses. J Comp Neurol 473:270-291.

Micevych P, Dominguez R (2009) Membrane estradiol signaling in the brain. Front Neuroendocrinol 30:315-327.

Micevych P, Kuo J, Christensen A (2009) Physiology of membrane oestrogen receptor signalling in reproduction. J Neuroendocrinol 21:249-256.

Mitra SW, Hoskin E, Yudkovitz J, Pear L, Wilkinson HA, Hayashi S, Pfaff DW, Ogawa S, Rohrer SP, Schaeffer JM, McEwen BS, Alves SE (2003) Immunolocalization of estrogen receptor beta in the mouse brain: comparison with estrogen receptor alpha. Endocrinology 144:2055-2067.

Mouret A, Gheusi G, Gabellec MM, de Chaumont F, Olivo-Marin JC, Lledo PM (2008) Learning and survival of newly generated neurons: when time matters. J Neurosci 28:11511-11516.

Mouret A, Murray K, Lledo PM (2009) Centrifugal drive onto local inhibitory interneurons of the olfactory bulb. Ann NY Acad Sci 1170:239-254.

Nagy AL, Ormerod BK, Mazzucco CA, Galea LAM (2006) Estradiolinduced enhancement in cell proliferation is mediated through estrogen receptors in the dentate gyrus of adult female rats. Drug Dev Res 66:142-149.

Nelson JF, Felicio LS, Osterburg HH, Finch CE (1992) Differential contributions of ovarian and extraovarian factors to age-related 
reductions in plasma estradiol and progesterone during the estrous cycle of C57BL/6J mice. Endocrinology 130:805-810.

Ormerod BK, Galea LA (2001) Reproductive status influences cell proliferation and cell survival in the dentate gyrus of adult female meadow voles: a possible regulatory role for estradiol. Neuroscience 102:369-379.

Pakarainen T, Zhang FP, Poutanen M, Huhtaniemi I (2005) Fertility in luteinizing hormone receptor-knockout mice after wild-type ovary transplantation demonstrates redundancy of extragonadal luteinizing hormone action. J Clin Invest 115:1862-1868.

Pawluski JL, Brummelte S, Barha CK, Crozier TM, Galea LA (2009) Effects of steroid hormones on neurogenesis in the hippocampus of the adult female rodent during the estrous cycle, pregnancy, lactation and aging. Front Neuroendocrinol 30:343-357.

Perez-Martin M, Azcoitia I, Trejo JL, Sierra A, Garcia-Segura LM (2003) An antagonist of estrogen receptors blocks the induction of adult neurogenesis by insulin-like growth factor-I in the dentate gyrus of adult female rat. Eur J Neurosci 18:923-930.

Petreanu L, Alvarez-Buylla A (2002) Maturation and death of adultborn olfactory bulb granule neurons: role of olfaction. J Neurosci 22:6106-6113.

Rochefort C, Gheusi G, Vincent JD, Lledo PM (2002) Enriched odor exposure increases the number of newborn neurons in the adult olfactory bulb and improves odor memory. J Neurosci 22:2679_ 2689.

Shingo T, Gregg C, Enwere E, Fujikawa H, Hassam R, Geary C, Cross JC, Weiss S (2003) Pregnancy-stimulated neurogenesis in the adult female forebrain mediated by prolactin. Science 299:117-120.

Smith MT, Pencea V, Wang Z, Luskin MB, Insel TR (2001) Increased number of BrdU-labeled neurons in the rostral migratory stream of the estrous prairie vole. Horm Behav 39:11-21.

Steiner B, Zurborg S, Hörster H, Fabel K, Kempermann G (2008) Differential 24h responsiveness of Prox1-expressing precursor cells in adult hippocampal neurogenesis to physical activity, environmental enrichment, and kainic acid-induced seizures. Neuroscience 154:521-529.

Stopfer M, Bhagavan S, Smith BH, Laurent G (1997) Impaired odour discrimination on desynchronization of odour-encoding neural assemblies. Nature 390:70-74.
Suzuki M, Wright LS, Marwah P, Lardy HA, Svendsen CN (2004) Mitotic and neurogenic effects of dehydroepiandrosterone (DHEA) on human neural stem cell cultures derived from the fetal cortex. Proc Natl Acad Sci U S A 101:3202-3207.

Suzuki S, Gerhold LM, Bottner M, Rau SW, Dela Cruz C, Yang E, Zhu H, Yu J, Cashion AB, Kindy MS, Merchenthaler I, Gage FH, Wise PM (2007) Estradiol enhances neurogenesis following ischemic stroke through estrogen receptors alpha and beta. J Comp Neurol 500:1064-1075.

Tanapat P, Hastings NB, Gould E (2005) Ovarian steroids influence cell proliferation in the dentate gyrus of the adult female rat in a dose- and time-dependent manner. J Comp Neurol 481:252-265.

Tanapat P, Hastings NB, Reeves AJ, Gould E (1999) Estrogen stimulates a transient increase in the number of new neurons in the dentate gyrus of the adult female rat. J Neurosci 19:5792-5801.

Temel S, Lin W, Lakhlani S, Jennes L (2002) Expression of estrogen receptor-alpha and cFos in norepinephrine and epinephrine neurons of young and middle-aged rats during the steroid-induced luteinizing hormone surge. Endocrinology 143:3974-3983.

Veyrac A, Didier A, Colpaert F, Jourdan F, Marien M (2005) Activation of noradrenergic transmission by alpha2-adrenoceptor antagonists counteracts deafferentation-induced neuronal death and cell proliferation in the adult mouse olfactory bulb. Exp Neurol 194:444456.

Veyrac A, Sacquet J, Nguyen V, Marien M, Jourdan F, Didier A (2009) Novelty determines the effects of olfactory enrichment on memory and neurogenesis through noradrenergic mechanisms. Neuropsychopharmacology 34:786-795.

Wersinger SR, Rissman EF (2000) Oestrogen receptor alpha is essential for female-directed chemo-investigatory behaviour but is not required for the pheromone-induced luteinizing hormone surge in male mice. J Neuroendocrinol 12:103-110.

Wesson DW, Keller M, Douhard Q, Baum MJ, Bakker J (2006) Enhanced urinary odor discrimination in female aromatase knockout (ArKO) mice. Horm Behav 49:580-586.

Wise PM, Dubal DB, Wilson ME, Rau SW, Liu Y (2001) Estrogens: trophic and protective factors in the adult brain. Front Neuroendocrinol 22:33-66.

Zhao C, Deng W, Gage FH (2008) Mechanisms and functional implications of adult neurogenesis. Cell 132:645-660. 